\title{
Mental Health Problems and Associated Predictors Among Bangladeshi Students
}

\section{Mohammed A. Mamun ${ }^{1,2} \cdot$ Md. Sharif Hossain ${ }^{1,2} \cdot$ Mark D. Griffiths $^{3}$}

Published online: 29 October 2019

(C) The Author(s) 2019

\begin{abstract}
Common mental health problems are regarded as public health concerns and can contribute to risky behaviors such as suicide among university students in extreme cases. However, there is a lack of studies concerning such issues in Bangladesh. The present study aimed to fill this knowledge gap by investigating the prevalence and associated risk predictors of depression, anxiety, and stress among Bangladeshi university students. The sample comprised 590 undergraduates attending Jahangirnagar University (Dhaka, Bangladesh) who completed an offline survey including sociodemographic questions, behavioral variables, and the 21-item Bangla Depression, Anxiety and Stress Scale (BDASS-21). The prevalence of moderate to the extremely severe levels of depression, anxiety, and stress was $52.2 \%, 58.1 \%$, and $24.9 \%$, respectively. There were no significant gender differences in depression, anxiety, and stress. Risk factors for depression included coming from a lower class family, being a cigarette smoker, and engaging in less physical exercise. Risk factors for anxiety and stress included being engaged in a relationship. The findings need to be further replicated among other Bangladeshi university students to help in the development of better intervention programs and appropriate support services targeting this vulnerable group including a focus of suicide prevention and awareness.
\end{abstract}

Keywords Mental health problems · Depression · Anxiety · Stress · Suicide risk · Bangladeshi students

\section{Introduction}

After completing secondary high school, students can face multiple potential problems in their new university environment. During this transitional period, students need to cope with the academic and

\section{Mark D. Griffiths}

mark.griffiths@ntu.ac.uk

Mohammed A. Mamun

mamunphi46@gmail.com

Md. Sharif Hossain

tanzimsharifju@gmail.com

Extended author information available on the last page of the article 
social demands that they encounter in university studies that help in their preparation for professional careers by the acquisition of professional knowledge, transferable skills, and evidence-informed attitudes (Bayram and Bilgel 2008; Kulsoom and Afsar 2015; ul Haq et al. 2018). For some students, the university environment can become unbearable and bring unexpected problems (such as living away from family and friends for the first time), and they may not have the psychological resilience to cope with such situations (Saeed et al. 2018; Taneja et al. 2018). Most undergraduate students have to undergo several psychosocial and psychological changes related to the development of an autonomous personal life (Alim et al. 2017a, b). Consequently, common mental health problems (MHPs) - such as depression, anxiety, and stress - are prevalent among contemporary university students, and these disorders appear to be increasing in number and severity due to these stressors and transitional events (Bayram and Bilgel 2008; Beiter et al. 2015; Hunt and Eisenberg 2010; Kulsoom and Afsar 2015; Nadeem et al. 2017; Saeed et al. 2018; Shamsuddin et al. 2013; Taneja et al. 2018; ul Haq et al. 2018).

Recent research has reported that approximately one-third of first-year undergraduate students report suffering any type of MHP in the past year (Bruffaerts et al. 2018), and these MHPs account for $30 \%$ of the global non-fatal disease burden (World Health Organization 2016). The global prevalence of moderate to extremely severe levels is $60.8 \%$ for depression, $73 \%$ for anxiety, and 62.4\% for stress (Bayram and Bilgel 2008; Beiter et al. 2015; Kulsoom and Afsar 2015; Nadeem et al. 2017; Saeed et al. 2018; Shamsuddin et al. 2013; Taneja et al. 2018; ul Haq et al. 2018). In Bangladesh, the prevalence of depression, anxiety, and stress has been reported to be as high as 54.3\%, 64.8\%, and 59.0\%, respectively (Alim et al. 2017a, b; Hossain et al. 2014; Mamun and Griffiths 2019; Mamun et al. 2019).

Recent research has also highlighted several contributing factors to increased stress, anxiety, and depression among students - most notably gender (male susceptibility in ul Haq et al. 2018, and female susceptibility in Mayer et al. 2016; Wahed and Hassan 2017), academic dissatisfaction, strained relationships, family and peer pressure, first year at university, high parental expectation, lack of financial support and hardships, sleep deprivation, future worries, loneliness, more time using internet, toxic psychological environment, academic pressure, workload, size of the academic curriculum, and endless test schedules (Mamun and Griffiths 2019; Mayer et al. 2016; Saeed et al. 2018; Silva and Figueiredo-Braga 2018; ul Haq et al. 2018). In Bangladesh, particularly Jahangirnagar University, where the present study was conducted, junior students have to face "ragging" (i.e., teasing or rudeness by senior students to first-year students, which can cause annoyance, harm and/or mental distress), which persists greatly in South Asian countries such as Bangladesh, India, etc.) (Garg 2009; Prothom Alo 2018). Ragging can lead to psychological distress, hospitalization (Prothom Alo 2018), and suicidal ideation (Garg 2009; Sharma and Bodh 2009) due to mental trauma of being ragged by senior students. Consequently, studies are needed to ensure the well-being and prevention of MHPs that may facilitate suicidal ideation among students.

Studies have found that it is not only the psychological morbidity of MHPs that has adverse effects on numerous daily functions and well-being of students (Bayram and Bilgel 2008; Saeed et al. 2018). MHPs also impact negatively on students' physical health and development, educational attainment (i.e., academic year percentage, grade point average), and quality of life, as well as a deteriorating influence on their own families, institutions, and on other people's lives (Bayram and Bilgel 2008; Bruffaerts et al. 2018). MHPs are also among the strongest predictors of suicide with approximately $90 \%$ of suicide victims having at least one mental disorder (Arafat and Mamun 2019; Shah et al. 2017; ul Haq et al. 2018) which is regarded as a public health crisis in Asian countries like Bangladesh (Arafat 2017, 2019; Shah et al. 2017). 
There is a lack of studies (and therefore a knowledge gap) concerning common MHPs in Bangladesh. There are few (if any) programs and interventions targeted at this vulnerable group (Hossain et al. 2014). This lack of knowledge has also hindered the initiation of bespoke education and public health policymaking of any country (Bayram and Bilgel 2008). Moreover, the recent occurrences of suicide (four suicides and one suicide rescued) among students also suggest a need to examine the existing mental health problems in Bangladesh because mental comorbidities can facilitate suicidal behaviors (Arafat and Mamun 2019; Shah et al. 2017). Consequently, the present study investigated the prevalence of depression, anxiety, and stress among Bangladeshi undergraduate students and their associated risk factors with respect to socio-demographics (e.g., gender, socioeconomic status of the family, permanent residency, studied faculty, etc.), and behavioral measures (e.g., smoking cigarettes, physical activities, internet use, etc.).

\section{Methods}

\section{Participants and Procedure}

The present cross-sectional study was conducted among undergraduate students of Jahangirnagar University (Dhaka, Bangladesh) and collected data from July to October 2018. The inclusion of the participants was anonymous and voluntary. Data from 635 participants were collected, but following the removal of incomplete questionnaires, 590 were retained for final analysis. Of these, 302 were men $(51.2 \%)$ and the mean age of the total sample was 24.12 years $(\mathrm{SD}=1.55$ years). Just over half of the total sample were first-year university students (51.4\%). The data were collected using a convenience sampling method via an offline self-reported paper survey at the respective departments and institutes of the university.

\section{Statistical analysis}

Data were analyzed using Statistical Package for Social Science (SPSS) version 22.0 and Microsoft Excel 2016. Microsoft Excel was used for data entry. The final descriptive statistics (e.g., frequencies, percentages, means, chi-squares, and Fisher's exact tests) were performed with SPSS 22.0. Categorical variables were compared with depression, anxiety, and stress separately using the chi-square tests and Fisher's exact tests. All significant variables in bivariate analysis were then entered into the binary logistic regression in both unadjusted and adjusted models with "depression," "anxiety," and "stress" as the dependent variables. The results of logistic regression were interpreted with $95 \%$ confidence intervals.

Ethics The study procedures were carried out according to the guidelines of the Declaration of Helsinki. Formal study permission was taken from respective authority. All participants were informed prior to data collection about the purpose of the study. Consent forms were signed by the participating students prior to data collection. Participant anonymity and confidentiality of data were ensured, and then participants were provided with information about the nature and purpose of the study, the procedure, and the right to withdraw their data from the study. 


\section{Measures}

\section{Sociodemographic measures}

Socio-demographic data were collected including age, gender, year of study, faculty of study, permanent residence (city or village), socioeconomic status (upper, middle, and lower class), relationship status (i.e., single, in a relationship, or married). Jahanginagar University comprises four Institutes and six Faculties (i.e., Mathematical and Physical Science, Biological Science, Social Science, Arts and Humanities, Business Studies, and Law). All the faculties but only one institute (Institute of Information Technology) were accessed for data collection. Due to the small size and for statistical purposes, participants from Business Studies were combined with Social Science, and the Institute of Information Technology was combined with Mathematical and Physical Science.

\section{Behavioral factors}

The present study also asked a few questions related to lifestyle. The cigarette smoking status of the participants was asked (simply "Yes" or "No"). Participants were additionally asked if they engaged in physical exercise for at least 20 min every day (e.g., walking, playing sports games, cycling, swimming, or any other activity). For sleep duration, participants were asked to report the average duration of sleep per day as normal $(6-7 \mathrm{~h})$, short $(<6 \mathrm{~h})$, or long $(>7 \mathrm{~h})$ (Mamun and Griffiths 2019). Finally, they were asked about internet use behaviors and overall time spent online as well as daily use (in hours).

\section{Bangla Depression Anxiety Stress Scale}

The Depression Anxiety Stress Scale is a self-report instrument for assessing depression, anxiety, and stress (Lovibond and Lovibond 1995). The 21-item Bangla Depression Anxiety Stress Scale (DASS-21) is a short version of the original 42-item scale. In the present study, the Bangla version of DASS-21 was used (Alim et al. 2017a, b). This scale comprises 21 items on a four-point Likert scale ranging from never (0) to always (3) and provides scores on three subscales - depression (seven items), anxiety (seven items), and stress (seven items). In the present study, moderate to extremely severe scores were used to categorize levels of depression, anxiety, and stress. The DASS is a well-established instrument with good to excellent psychometric properties in non-clinical samples (Ostovar et al. 2016). In the original Bangla version, Cronbach's alphas for the depression, anxiety, and stress subscales were 0.99, 0.96, and 0.96, respectively (Alim et al. 2017a, b). For the present study, the Cronbach's alphas for the depression, anxiety, and stress subscales were $0.77,0.78$, and 0.83 , respectively, with an overall Cronbach's $\alpha$ of 0.91 .

\section{Results}

With regard to socioeconomic status, the majority of students $(87.8 \%)$ were from a middleclass family. Four-fifths of the sample were single (80.5\%), 14.6\% were cigarette smokers, and $44.6 \%$ performed physical exercise every day. The majority of the sample were normal sleepers $(57.3 \%$ ) and $47.6 \%$ used the internet for $2-5 \mathrm{~h}$ per day (Table 1). The levels of 
depression, anxiety, and stress were assessed by using the summated scores of three individual subscales, where higher scores indicate higher levels of depression, anxiety, and stress. Results demonstrated that $52.2 \%$ of the participants moderate to extremely severe depression, $58.1 \%$ had moderate to extremely severe anxiety, and $24.9 \%$ had moderate to extremely severe stress (Table 1).

Depressed participants were significantly more likely than non-depressed participants to be from the lower-class family $\left(\chi^{2}=13.728, d f=2, p<0.001\right)$, be a cigarette smoker $\left(\chi^{2}=3.762\right.$, $d f=1, p<0.05)$, engage in less regular daily physical activities $\left(\chi^{2}=9.030, d f=1, p<0.001\right)$, have more or less sleep than recommended $\left(\chi^{2}=13.929, d f=2, p<0.001\right)$, use the internet for more than 5 h per day $\left(\chi^{2}=9.618, d f=2, p=0.008\right)$, be anxious $\left(\chi^{2}=100.284, d f=1, p<\right.$ $0.001)$, and suffer from stress $\left(\chi^{2}=95.413, d f=1, p<0.001\right)$. Anxious participants were significantly more likely than non-anxious participants to be in a relationship $\left(\chi^{2}=8.212, d f=\right.$ $1, p=0.004)$, and suffer from depression $\left(\chi^{2}=100.284, d f=1, p<0.001\right)$ and stress $\left(\chi^{2}=\right.$ $77.205, d f=1, p=0.008)$. Finally, stressed participants were significantly more likely than non-stressed participants to be in a relationship $\left(\chi^{2}=3.933, d f=1, p=0.047\right)$, use the internet for more than $5 \mathrm{~h}$ per day $\left(\chi^{2}=9.618, d f=2, p=0.008\right)$, and suffer from depression $\left(\chi^{2}=\right.$ 95.413, $d f=1, p<0.001)$ and anxiety $\left(\chi^{2}=77.205, d f=1, p=0.008\right)$ (Table 1).

The regression analysis showed statistically significant associations between the three included MHPs and all variables of interest (i.e., socio-demographic variables, behavioral variables, and psychopathology — see Table 2). The unadjusted model demonstrated that the following characteristics were significant risk factors for depression: being from a lowerincome family, less physical activities performers, having sleep disturbances (longer or shorter sleeping hour), using the internet for more than five hours daily, and having anxiety and stress. For anxiety, the significant risk factors were being in a relationship, and having depression and stress. For stress, the significant risk factors were engaging in a relationship, having sleep disturbance, using the internet for more than $5 \mathrm{~h}$ daily, and having depression and anxiety (Table 2).

\section{Discussion}

Mental health problems (MHPs) are regarded as a public health concern among university students and can be a great source of psychological suffering and increase the risk of suicidal behaviors (Arafat and Mamun 2019; Bayram and Bilgel 2008; Beiter et al. 2015; Saeed et al. 2018; Shah et al. 2017; ul Haq et al. 2018). Although MHP research has attracted the attention of the researchers globally, it is very much understudied in Bangladesh. Only a few studies have been conducted in Bangladesh addressing the MHPs. Consequently, there is a knowledge gap in Bangladesh which is why the present study assessed depression, anxiety, and stress among university students more generally across a wide range of different subjects as opposed to medical students only.

Based on Bangla DASS-21 scores, results indicated that just over a half of the participants were classed as having moderate to extremely severe levels of depression (52.2\%) compared to $58.1 \%$ with moderate to extremely severe levels of anxiety, and $24.9 \%$ with moderate to extremely severe level stress. Compared to the previous Bangladeshi study, the prevalence of depression, anxiety, and stress among medical students was less than a wider range of students in the present study, especially for stress (54.3\% depression, $64.8 \%$ anxiety, and 59.0\% stress) (Alim et al. 2017a, b). Another recent study conducted among the northern Bangladeshi 


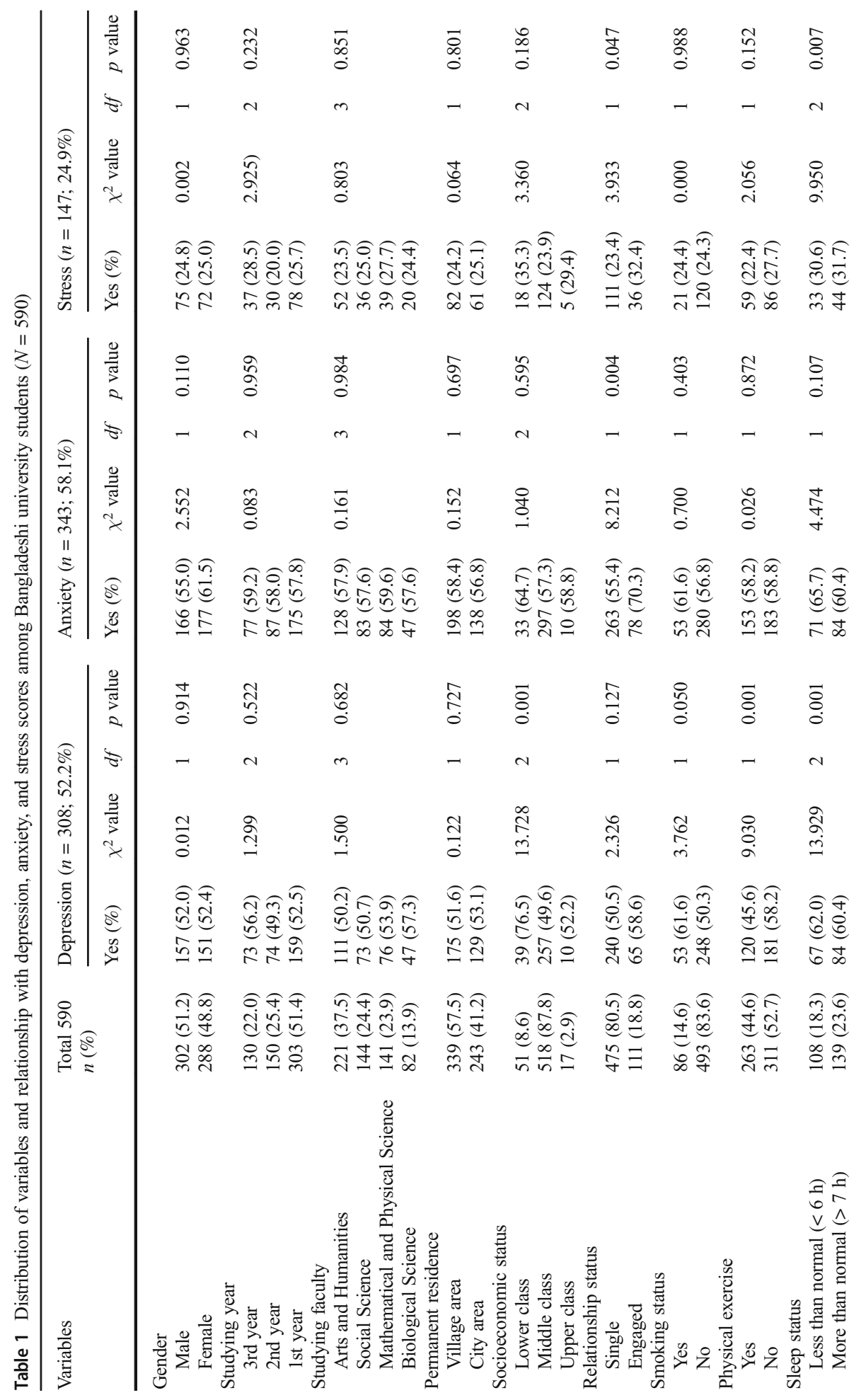




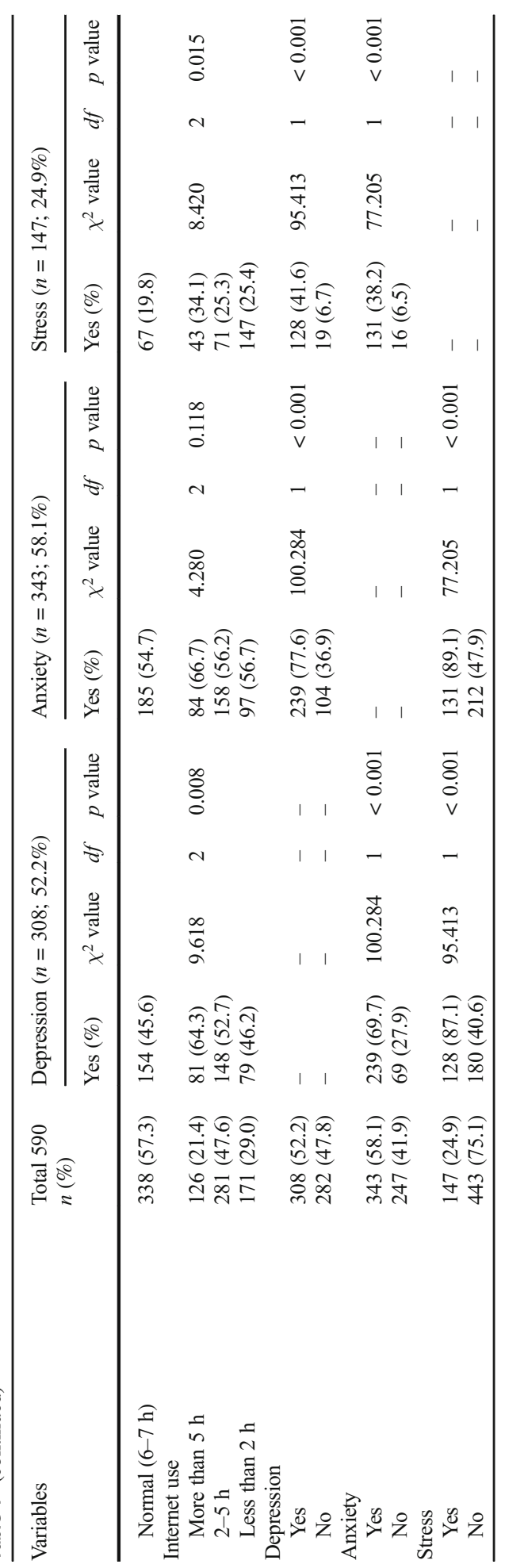




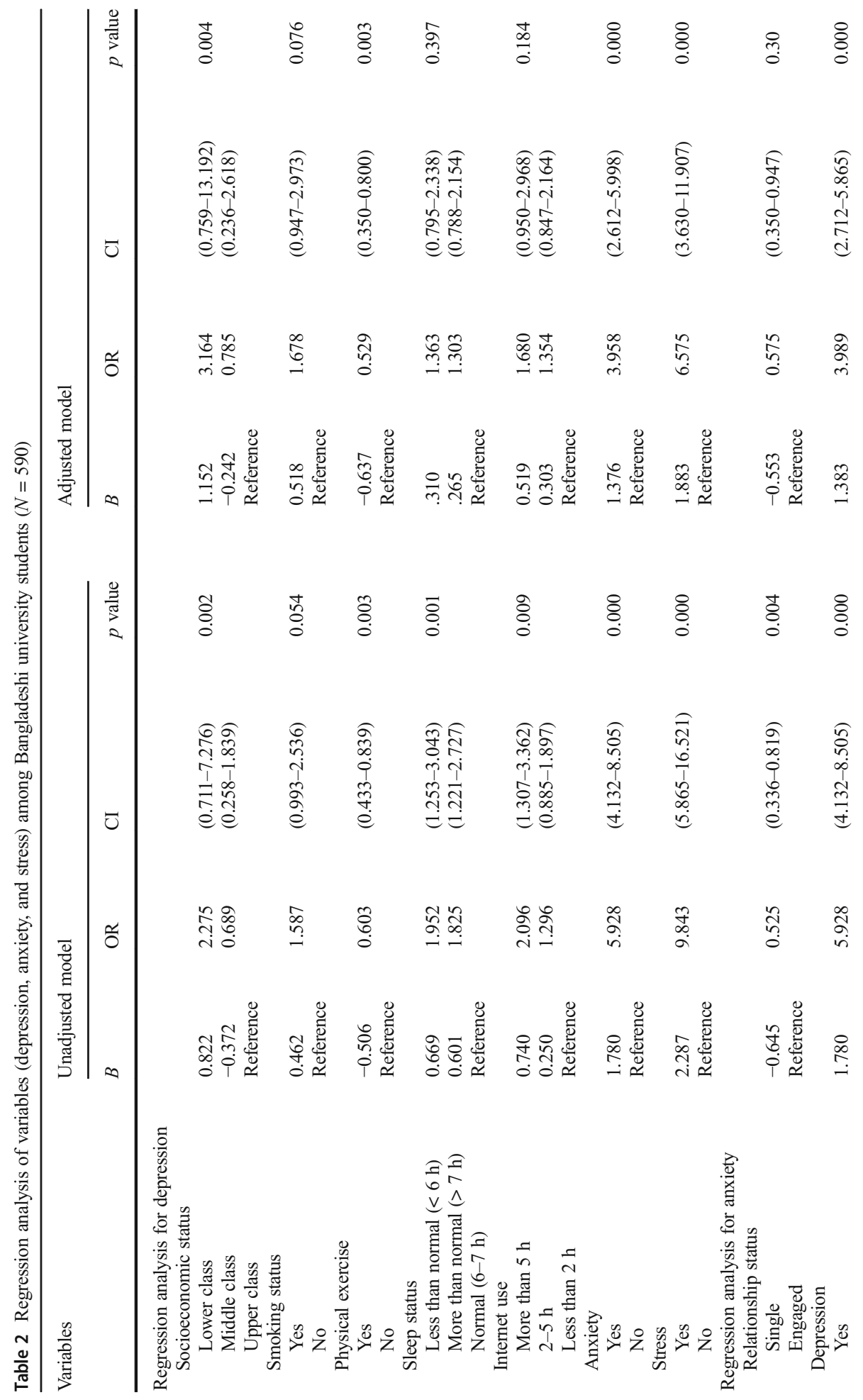




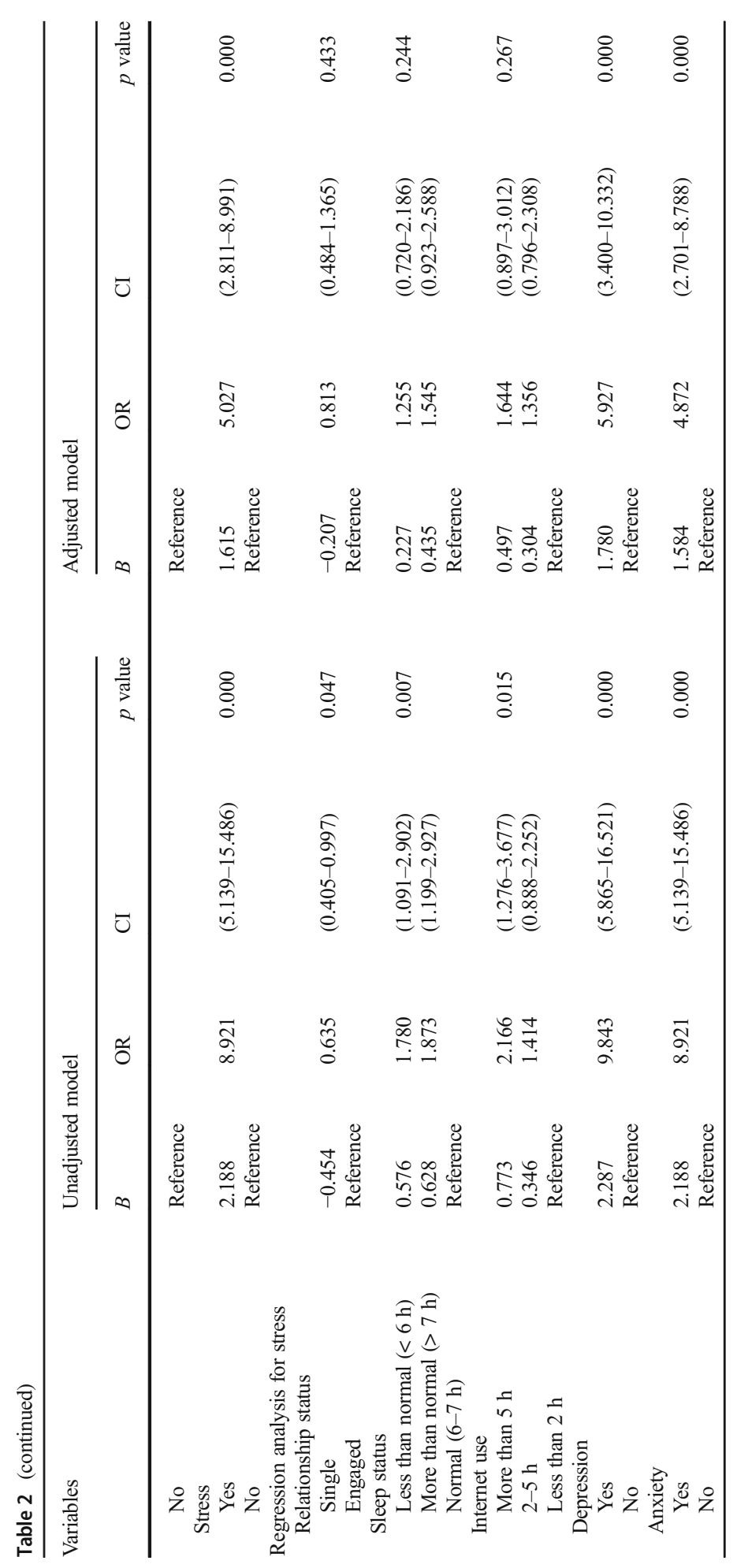


graduate students reported the prevalence rates of depression to be $49.6 \%$, anxiety to be $53.2 \%$, and stress to be $26.4 \%$ (Mamun et al. 2019).

Compared the prevalence levels of depression using DASS globally, the prevalence of depression in the present study was higher than studies on students in Pakistan (ranged from 2 to 48.4\%; Nadeem et al. 2017; ul Haq et al. 2018; Yusoff et al. 2013), India (32.0\%; Taneja et al. 2018), Malaysia (37.2\%; Shamsuddin et al. 2013), Jordan (28.5\%; Hamaideh 2018), USA (23\%; Beiter et al. 2015), Turkey (27.1\%; Bayram and Bilgel 2008), and Saudi Arabia (30 to 43\%; Kulsoom and Afsar 2015), but less than Egypt (60\%; Wahed and Hassan 2017). Compared to the prevalence levels of anxiety using DASS globally, the prevalence of anxiety in the present study was lower than in two Pakistani studies (64 to 73.4\%; Nadeem et al. 2017; ul Haq et al. 2018), Egyptian (64.3\%; Wahed and Hassan 2017), and Malaysia (63\%; Shamsuddin et al. 2013) study, but higher than in one Pakistani study (54.5\%; Yusoff et al. 2013), Jordan (28.5\%; Hamaideh 2018), Indian (43.8\%; Taneja et al. 2018), USA (25\%; Beiter et al. 2015), and Turkey (47.1\%; Bayram and Bilgel 2008). Compared to the prevalence levels of stress using the DASS globally, the prevalence of stress in the present study was lower than two Pakistani studies (38.5 to 47.6\%; Nadeem et al. 2017; ul Haq et al. 2018), USA (26\%; Beiter et al. 2015), Turkey (27\%; Bayram and Bilgel 2008), Saudi Arabia (30 to 41\%; Kulsoom and Afsar 2015), and Egypt (62.4\%; Wahed and Hassan 2017), but higher than in one Pakistani study (3.6\%; Yusoff et al. 2013), Malaysia (23.7\%; Shamsuddin et al. 2013), and Jordan (22.6\%; Hamaideh 2018).

Based on the findings of previous studies surveying students, depression and anxiety prevalence rates were relatively higher in the present study compared to the aforementioned studies, whereas the prevalence rate for stress in the present study was more comparable to these studies. This higher level of overall MHPs prevalence may be higher due to ragging and other issues existing in the university; the participants were sampled from, as well as other more conventional reasons (i.e., lack of social and/or family support, future worries, toxic psychological environment, academic pressure, academic workload, size of the academic curriculum, and endless test schedules) (Bayram and Bilgel 2008; Bruffaerts et al. 2018; Garg 2009; Mayer et al. 2016; Prothom Alo 2018; Saeed et al. 2018; Silva and Figueiredo-Braga 2018; ul Haq et al. 2018). Because MHPs can hamper the well-being and academic functioning of students and (in extreme cases) can lead to suicidal ideation (Arafat and Mamun 2019; Bruffaerts et al. 2018; Shah et al. 2017; ul Haq et al. 2018), special attention is needed for preventing MHPs among this vulnerable group along with awareness raising of the factors contributing to the risk of MHPs.

MHPs tend to affect more females than males (Bayram and Bilgel 2008; Beiter et al. 2015; Ferrie et al. 2002; Hamaideh 2018; Shamsuddin et al. 2013), although a few studies suggest that male students are also prone to high levels of depression, anxiety, and stress (Demirbatir 2012; Nadeem et al. 2017; ul Haq et al. 2018). In the present study, no significant gender differences were found in relation to depression, anxiety, or stress, and were very similar to Bayram and Bilgel's (2008) study which found no significant differences between gender and depression, anxiety, and stress. Many factors can impact on mental well-being including economic hardship, reductions in income, debt, house repossession, house evictions, job loss, insecurity, social disintegration, family disruption, and poor quality of life (Bayram and Bilgel 2008; Demirbatir 2012; Economou et al. 2013). A longitudinal study by Lorant et al. (2007) also reported that individuals in the lowest socioeconomic group have an increased likelihood of depression compared to those in the highest socioeconomic group. Similar findings were found in the present study, although a different study suggested that there was no relationship 
between the socioeconomic status of the family and MHPs among students (Shamsuddin et al. 2013).

In the present study, being engaged in a relationship was found to be a predictor of developing higher levels of anxiety and stress in the present study. This may have been because the students were living away from their partner (causing them mental distress) and/ or because they spent little time with their partner because of their academic workload. Some research suggests that being unmarried can increase the likelihood of stress, anxiety, and depression (Wahed and Hassan 2017), but here, "being unmarried" will also include both single individuals and those in relationships but not married. Some authors have claimed that being in a relationship can be a risk factor in developing major depression, but this is often associated with financial issues (Economou et al. 2013) which could also be a factor in the present study but was not specifically addressed in the questions asked. However, Meutia et al. (2018) assert that marital status does not play any role in the occurrence of anxiety symptoms. Consequently, further research regarding the role of relationship status in MHPs is warranted.

Sleep plays a vital role of human well-being by helping in maintaining individuals' biological rhythm. The associations between lower sleep quality and symptoms of anxiety and depression are well established, to the extent that sleep disturbance is listed as a symptom of specific MHPs in DSM-5 (American Psychiatric Association 2013). In the present study, sleep disturbance (both too much or too little sleep) contributed to the risk of experiencing depression and stress. Research also shows that cigarette smoking can be associated with experiencing depression, anxiety, and stress symptoms (Kulsoom and Afsar 2015), although smoking cigarettes is likely to be a mechanism to overcome (at least temporarily) the feelings of stress, anxiety, and depression. The same study (i.e., Kulsoom and Afsar 2015) also reported the role of less physical exercise contributing to depressive symptoms, whereas this study suggests to less physical activities that contribute to the risk of being depressed and anxious.

The present study also found that spending more time daily on the internet (i.e., spending more than $5 \mathrm{~h}$ a day) and supports the psychological literature that problematic internet use is associated with common MHPs including depression, anxiety, stress, insomnia, loneliness, and lower self-esteem (Dieris-Hirche et al. 2017; Mamun et al. 2019; Ostovar et al. 2016; Younes et al. 2016). However, whether these symptoms are caused by problematic internet use or are a consequence of it (or both) has yet to be conclusively demonstrated. Longitudinal studies are needed to examine such relationships and associations. Moreover, the bivariate associations between depression-anxiety, anxiety-stress, and depression-stress were found to be statistically significant and risk factors for each other (depression, anxiety, and stress) as has been found in previous studies (e.g., Demirbatir 2012; Nadeem et al. 2017; Silva and Figueiredo-Braga 2018). This provides further support for using the DASS in the present study.

\section{Implications of the study}

Although the DASS is not a diagnostic instrument, it is worth remembering that the prevalence rates of moderate to extreme depression, anxiety, and stress in the present study suggest that attention is needed from health care professionals and university administrative personnel (Bayram and Bilgel 2008; Shamsuddin et al. 2013). Based on the findings of the present study, common MHPs were highly prevalent among the students. Previously, MHPs were suggested as being the mediators of committing suicide and studies have shown that $90 \%$ of suicide victims have at least one mental disorder (Arafat et al. 2018a, b; Arafat and Mamun 2019; 
Shah et al. 2017; ul Haq et al. 2018). Moreover, in Bangladesh, suicide and suicidal behavior awareness appears to be growing and has now been embedded as a public health problem by policymakers in the country (Arafat 2017, 2019; Arafat et al. 2018a, b; Shah et al. 2017). Given that the rate of Bangladeshi university student suicides is increasing (Arafat 2017, 2018; Arafat and Mamun 2019), the relatively high levels of MHPs found in the present study suggest that targeted prevention should include student support centers, online-based interventions, and curriculum-based programs concerning suicide awareness (Arafat 2018; Arafat and Mamun 2019). Moreover, a special focus should be on mental health literacy because it can improve individuals' psychological well-being by facilitating the identification of disorders in the first place, treatment-seeking by affected individuals, preventive initiatives, and increased medication compliance (Arafat et al. 2018a, b, 2019). Moreover, these findings need to be further explored to help facilitate the development of better intervention programs and appropriate support services targeting this vulnerable group.

\section{Limitations}

This study is not without limitations. Firstly, the present study was cross-sectional in nature, and so the causal relationships between depression, anxiety, and stress, and associated sociodemographic and behavioral factors cannot be delineated based on these data alone. The study was also limited by the relatively small sample size using convenience sampling. The findings are also limited by the fact that the data were self-report which might have influenced results via various biases (e.g., method bias, social desirability bias, memory recall bias) (Mamun and Griffiths 2019). So, no generalizations can be made to other students who live outside of Dhaka or Bangladesh more generally as the data were collected from just a single university (i.e., Jahangirnagar University). The present research needs to be replicated using other bigger and more representative samples both inside and outside of Bangladesh.

\section{Conclusions}

The present study provides some baseline data (concerning prevalence and potential risk factors) in relation to depression, anxiety, and stress among university students in Bangladesh. Along with potential risk factors, the study reported a higher prevalence of depression and anxiety than found in other studies worldwide, although the prevalence of stress was similar to that found elsewhere globally. Such findings may play an important role in implementing mental health support programs as well as facilitating ideas for longitudinal research to assess the causality and relationships between MHPs and a wide range of individual, situational, and structural variables often associated with them.

Funding Information This work is self-funded.

\section{Compliance with Ethical Standards}

Conflict of Interest The authors declare that they do not have any interests that could constitute a real, potential or apparent conflict of interest with respect to their involvement in the publication. The authors also declare that they do not have any financial or other relations (e.g. directorship, consultancy or speaker fee) with companies, trade associations, unions or groups (including civic associations and public interest groups) that may gain or lose financially from the results or conclusions in the study. Sources of funding are acknowledged. 
Ethical Approval All procedures performed in this study involving human participants were in accordance with the ethical standards of University's Research Ethics Board and with the 1975 Helsinki Declaration.

Informed Consent Informed consent was obtained from all participants.

Open Access This article is distributed under the terms of the Creative Commons Attribution 4.0 International License (http://creativecommons.org/licenses/by/4.0/), which permits unrestricted use, distribution, and reproduction in any medium, provided you give appropriate credit to the original author(s) and the source, provide a link to the Creative Commons license, and indicate if changes were made.

\section{References}

Alim, S. M. A. H. M., Kibria, S. M. E., Islam, M. J., Uddin, M. Z., Nessa, M., Wahab, M. A., \& Islam, M. M. (2017a). Translation of DASS 21 into Bangla and validation among medical students. Bangladesh Journal of Psychiatry, 28(2), 67-70.

Alim, S. M. A. H. M., Rabbani, M. G., Karim, E., Mullick, M. S. I., Al Mamun, A., \& Khan, M. Z. R. (2017b). Assessment of depression, anxiety and stress among first year MBBS students of a public medical college, Bangladesh. Bangladesh Journal of Psychiatry, 29(1), 23-29.

American Psychiatric Association. (2013). Diagnostic and statistical manual of mental disorders (Fifth ed.). Arlington: American Psychiatric Publishing.

Arafat, S. M. Y. (2017). Suicide in Bangladesh: A mini review. Journal of Behavioral Health, 6(1), 66-69.

Arafat, S. M. Y. (2018). Suicide prevention activities in Bangladesh. Asian Journal of Psychiatry, $36,38$.

Arafat, S.M.Y. (2019). Current challenges of suicide and future directions of management in Bangladesh: A systematic review. Global Psychiatry. DIO: https://doi.org/10.2478/gp-2019-0001.

Arafat, S. Y., \& Mamun, M. A. A. (2019). Repeated suicides in the University of Dhaka (November 2018): Strategies to identify risky individuals. Asian Journal of Psychiatry, 39, 84-85.

Arafat, S. M. Y., Akter, H., \& Mali, B. (2018a). Psychiatric morbidities and risk factors of suicidal ideation among patients attending for psychiatric services at a tertiary teaching hospital in Bangladesh. Asian Journal of Psychiatry, 34, $44-46$.

Arafat, S. Y., Majumder, M. A. A., Kabir, R., Papadopoulos, K., \& Uddin, M. S. (2018b). Health literacy in school. In Optimizing health literacy for improved clinical practices (pp. 175-197). IGI Global.

Arafat, S. Y., Mamun, M. A. A., \& Uddin, M. S. (2019). Depression literacy among first-year university students: A cross-sectional study in Bangladesh. Global Psychiatry. https:/doi.org/10.2478/gp-2019-0002.

Bayram, N., \& Bilgel, N. (2008). The prevalence and socio-demographic correlations of depression, anxiety and stress among a group of university students. Social Psychiatry and Psychiatric Epidemiology, 43(8), 667-672.

Beiter, R., Nash, R., McCrady, M., Rhoades, D., Linscomb, M., Clarahan, M., \& Sammut, S. (2015). The prevalence and correlates of depression, anxiety, and stress in a sample of college students. Journal of Affective Disorders, 173, 90-96.

Bruffaerts, R., Mortier, P., Kiekens, G., Auerbach, R. P., Cuijpers, P., Demyttenaere, K., et al. (2018). Mental health problems in college freshmen: Prevalence and academic functioning. Journal of Affective Disorders, $225,97-103$.

Demirbatir, R. E. (2012). Undergraduate music student's depression, anxiety and stress levels: A study from Turkey. Procedia-Social and Behavioral Sciences, 46, 2995-2999.

Dieris-Hirche, J., Bottel, L., Bielefeld, M., Steinbüchel, T., Kehyayan, A., Dieris, B., \& te Wildt, B. (2017). Media use and internet addiction in adult depression: A case-control study. Computers in Human Behavior, 68, 96-103.

Economou, M., Madianos, M., Peppou, L. E., Patelakis, A., \& Stefanis, C. N. (2013). Major depression in the era of economic crisis: A replication of a cross-sectional study across Greece. Journal of Affective Disorders, 145(3), 308-314.

Ferrie, J. E., Shipley, M. J., Stansfeld, S. A., \& Marmot, M. G. (2002). Effects of chronic job insecurity and change in job security on self reported health, minor psychiatric morbidity, physiological measures, and health related behaviours in British civil servants: The Whitehall II study. Journal of Epidemiology \& Community Health, 56(6), 450-454.

Garg, R. (2009). Ragging: A public health problem in India. Indian Journal of Medical Sciences, 63(6), $263-271$.

Hamaideh, S. H. (2018). Alexithymia among Jordanian university students: Its prevalence and correlates with depression, anxiety, stress, and demographics. Perspectives in Psychiatric Care, 54(2), 274-280. 
Hossain, M. D., Ahmed, H. U., Chowdhury, W. A., Niessen, L. W., \& Alam, D. S. (2014). Mental disorders in Bangladesh: A systematic review. BMC Psychiatry, 14(1), 216.

Hunt, J., \& Eisenberg, D. (2010). Mental health problems and help-seeking behavior among college students. Journal of Adolescent Health, 46(1), 3-10.

Kulsoom, B., \& Afsar, N. A. (2015). Stress, anxiety, and depression among medical students in a multiethnic setting. Neuropsychiatric Disease and Treatment, 11, 1713-1722.

Lorant, V., Croux, C., Weich, S., Deliège, D., Mackenbach, J., \& Ansseau, M. (2007). Depression and socioeconomic risk factors: 7-year longitudinal population study. British Journal of Psychiatry, 190(4), $293-298$.

Lovibond, P. F., \& Lovibond, S. H. (1995). Manual for the Depression Anxiety Stress Scales (2nd ed.). Sydney: Psychology Foundation.

Mamun, M. A. A., \& Griffiths, M. D. (2019). The association between Facebook addiction and depression: A pilot survey study among Bangladeshi students. Psychiatry Research, 271, 628-633.

Mamun, M. A., Rafi, M. A., Al Mamun, A. H. M. S., Hasan, M. Z., Akter, K., Hsan, K., \& Griffiths, M. (2019). Prevalence and psychiatric risk factors of excessive internet use among Northern Bangladeshi job-seeking graduate students: A pilot study. International Journal of Mental Health and Addiction. doi:https://oi. org/10.1007/s11469-019-00066-5.

Marthoenis, M., Meutia, I., Fathiariani, L., \& Sofyan, H. (2018). Prevalence of depression and anxiety among college students living in a disaster-prone region. Alexandria Journal of Medicine, 54(4), 337-340.

Mayer, F. B., Santos, I. S., Silveira, P. S. P., Lopes, M. H. I., de Souza, A. R. N. D., Campos, E. P., et al. (2016). Factors associated to depression and anxiety in medical students: A multicenter study. BMC Medical Education, 16(1), 282.

Nadeem, M., Ali, A., \& Buzdar, M. A. (2017). The association between Muslim religiosity and young adult college students' depression, anxiety, and stress. Journal of Religion and Health, 56(4), 1170-1179.

Ostovar, S., Allahyar, N., Aminpoor, H., Moafian, F., Nor, M. B. M., \& Griffiths, M. D. (2016). Internet addiction and its psychosocial risks (depression, anxiety, stress and loneliness) among Iranian adolescents and young adults: A structural equation model in a cross-sectional study. International Journal of Mental Health and Addiction, 14(3), 257-267.

Prothom Alo (2018). JU student traumatised by ragging. Retrieved March 25, 2019, from: https://en.prothomalo. com/youth/news/170935/JU-student-traumatised-by-ragging.

Saeed, H., Saleem, Z., Ashraf, M., Razzaq, N., Akhtar, K., Maryam, A., et al. (2018). Determinants of Anxiety and Depression Among University Students of Lahore. International Journal of Mental Health and Addiction, 16(5), 1283-1298.

Shah, M., Ali, M., Ahmed, S., \& Arafat, S. M. (2017). Demography and risk factors of suicide in Bangladesh: A six-month paper content analysis. Psychiatry Journal, 2017, e5.

Shamsuddin, K., Fadzil, F., Ismail, W. S. W., Shah, S. A., Omar, K., Muhammad, N. A., et al. (2013). Correlates of depression, anxiety and stress among Malaysian university students. Asian Journal of Psychiatry, 6(4), 318-323.

Sharma, K. N., \& Bodh, A. (2009). Medical student killed in ragging. Times of India, March 10. Retrieved March 25 2019, from: https://timesofindia.indiatimes.com/india/Medical-student-killed-inragging/articleshow/4247603.cms

Silva, R. G., \& Figueiredo-Braga, M. (2018). Evaluation of the relationships among happiness, stress, anxiety, and depression in pharmacy students. Currents in Pharmacy Teaching and Learning, 10(7), 903-910.

Taneja, N., Sachdeva, S., \& Dwivedi, N. (2018). Assessment of depression, anxiety, and stress among medical students enrolled in a medical college of New Delhi, India. Indian Journal of Social Psychiatry, 34(2), 157-162.

ul Haq, M. A., Dar, I. S., Aslam, M., \& Mahmood, Q. K. (2018). Psychometric study of depression, anxiety and stress among university students. Journal of Public Health, 26(2), 211-217.

Wahed, W. Y. A., \& Hassan, S. K. (2017). Prevalence and associated factors of stress, anxiety and depression among medical Fayoum University students. Alexandria Journal of Medicine, 53(1), 77-84.

World Health Organization (2016). Investing in treatment for depression and anxiety leads to fourfold return, April 10. Retrieved March 25, 2019, from https://www.who.int/en/news-room/detail/13-04-2016-investingin-treatment-for-depression-and-anxiety-leads-to-fourfold-return.

Younes, F., Halawi, G., Jabbour, H., El Osta, N., Karam, L., Hajj, A., \& Khabbaz, L. R. (2016). Internet addiction and relationships with insomnia, anxiety, depression, stress and self-esteem in university students: A crosssectional designed study. PLoS One, 11(9), e0161126.

Yusoff, M. S. B., Rahim, A. F. A., Baba, A. A., Ismail, S. B., \& Pa, M. N. M. (2013). Prevalence and associated factors of stress, anxiety and depression among prospective medical students. Asian Journal of Psychiatry, $6(2), 128-133$. 
Publisher's Note Springer Nature remains neutral with regard to jurisdictional claims in published maps and institutional affiliations.

\section{Affiliations}

\section{Mohammed A. Mamun ${ }^{1,2} \cdot$ Md. Sharif Hossain ${ }^{1,2}$ - Mark D. Griffiths ${ }^{3}$}

1 Department of Public Health \& Informatics, Jahangirnagar University, Dhaka, Bangladesh

2 Undergraduate Research Organization, Dhaka, Bangladesh

3 International Gaming Research Unit, Psychology Department, Nottingham Trent University, 50 Shakespeare Street, Nottingham NG1 4FQ, UK 